\title{
Molecular characterization of class 1 integrons and antimicrobial resistance in Aeromonas strains from foodborne outbreak-suspect samples and environmental sources in Taiwan
}

\author{
Yu-Chang Chang ${ }^{\mathrm{a}, \mathrm{b}}$, Daniel Yang-Chih Shih ${ }^{\mathrm{b}, *}$, Jan-Yi Wang ${ }^{\mathrm{b}}$, Shang-Shyng Yang ${ }^{\mathrm{a}, *}$ \\ anstitute of Microbiology and Biochemistry, National Taiwan University, Taipei 106, Taiwan \\ ${ }^{\mathrm{b}}$ Food Microbiology Division, Bureau of Food and Drug Analysis, Department of Health, Executive Yuan, Taipei 115, Taiwan \\ Received 2 March 2007; accepted 18 April 2007
}

\begin{abstract}
One hundred thirty-three Aeromonas spp. isolates were examined for multiple antibiotic resistance phenotypes and prevalence of class 1 integron sequences. Twenty-four $(18.0 \%)$ of these isolates contained class 1 integron. Seven different class 1 integrons were found among 24 strains, with a total of 10 different gene cassettes encoding for resistance to trimethoprim ( $d$ fr 12 and $d f r 2 d)$, aminoglycosides ( $a a d A 1$ and aadA2), $\beta$-lactam antibiotics (oxa2), chloramphenicol (catB3 and catB8), quaternary ammonium amines (qacE2), and 2 ORFs (orfD and $o r f F$ ) with unknown function. Rate of antibiotic resistance was different between integron-positive and integron-negative strains. Trimethoprim and trimethoprim-sulphamethoxazole resistances were commonly associated with integron, and all of integron-positive isolates were multiple resistant to more than 3 agents. Resistance to as many as 10 antimicrobial agents were observed in integron-positive strains. Several cassette arrays of class 1 integrons identified in this study were not previously reported in Aeromonas strains. This study demonstrates the wide distribution of class 1 integron in Aeromonas spp. isolated from foodborne outbreak-suspect samples and environmental sources in Taiwan.
\end{abstract}

(C) 2007 Elsevier Inc. All rights reserved.

Keywords: Aeromonas spp.; Antibiotic resistance; Integron; Multiple resistance

\section{Introduction}

Aeromonads are widespread in natural habitats, and some species cause both gastrointestinal and extraintestinal infectious diseases in human (Kirov, 1997). Aeromonas gastroenteritis is generally self-limiting, and antibiotic treatment is unnecessary. However, for extraintestinal infections, the susceptibility patterns should be known to implement appropriate therapy (Vila et al., 2002). Reports from many parts of the world suggest that members of

* Corresponding authors. Daniel Yang-Chih Shih is to be contacted at Food Microbiology Division, Bureau of Food and Drug Analysis, Department of Health, Executive Yuan, Taipei 115, Taiwan. ShangShyng Yang, Institute of Microbiology and Biochemistry, National Taiwan University, Taipei 106, Taiwan.

E-mail addresses: shihdyc@nlfd.gov.tw (D.Y.-C. Shih), ssyang@ntu.edu.tw (S.-S. Yang).

0732-8893/\$ - see front matter (C) 2007 Elsevier Inc. All rights reserved. doi:10.1016/j.diagmicrobio.2007.04.007 aeromonads readily develop single or multiple antibiotic resistances (Ko et al., 1996; Goñi-Urriza et al., 2000; Schmidt et al., 2001; Palú et al., 2006). The emergence and dissemination of antibiotic-resistant bacteria are a serious concern worldwide. The dissemination of antibiotic resistance genes by horizontal gene transfer has led to the rapid emergence of antibiotic resistance among bacteria, and acquisition of antibiotic resistance genes is facilitated by mobile genetic elements, such as integrons (Ploy et al., 2000). Integrons have been found to play an important role in the carriage and dissemination of antibiotic resistance genes (Fluit and Schmitz, 1999). Integrons are able to capture one or more gene cassettes from the environment and incorporate them by using sitespecific recombination. The role of integrons and gene cassettes in the dissemination of multidrug resistance in Gram-negative bacteria is well established (Hall and Stokes, 1993). Based on the sequences of integrase 
genes, at least 8 different classes of integrons have been described in Gram-negative bacteria (Nield et al., 2001).

Class 1 integrons are most commonly found in clinical isolates of Gram-negative bacteria and are strongly associated with multiple antibiotic resistances (Bass et al., 1999; Goldstein et al., 2001). These elements contribute to the spread of genetic determinants of antimicrobial resistance by horizontal gene transfer; although not mobile themselves, they are frequently associated to plasmids and transposons (Fluit and Schmitz, 1999; Martinez-Freijo et al., 1999). Class 1 integrons carry integrase gene (intI1), which code for the site-specific recombinase responsible for cassette insertion (Martinez and de la Cruz, 1990; Collis et al., 1993), and include the attIl site where the cassettes are integrated and a promoter, $\mathrm{P}_{\mathrm{c}}$, is responsible for the transcription of the cassette-encoded genes (Collis and Hall, 1995; Partridge et al., 2000). Gene cassette contains a single antibiotic resistance gene and a 59-base element (or attC site) downstream of the gene, which is responsible for recombination events (Collis et al., 2002).

Data on antimicrobial resistance in Aeromonas spp. are commonly obtained from clinical isolates of human, food, and environmental samples (Neyts et al., 2000; Radu et al., 2003) because they are important vehicles of dissemination of this pathogen. However, only a few studies have, to date, addressed the prevalence of class 1 integrons among environmental bacteria (Rosser and Young, 1999; Schmidt et al., 2001). In this study, we have determined the antimicrobial resistance rates and analyzed the class 1 integron population in strains of Aeromonas isolates from foodborne outbreak-suspect samples and environmental sources in Taiwan.

\section{Materials and methods}

\subsection{Bacterial isolates and antimicrobial susceptibility}

A total of 133 Aeromonas spp. were obtained from 3 sources: foodborne outbreak-suspect samples $(n=80)$, aquatic animal $(n=26)$, and poultry $(n=27)$. Of these, 50 were Aeromonas caviae, 45 Aeromonas hydrophila, 31 Aeromonas veronii bv. sobria (otherwise known as $A$. sobria), and 6 Aeromonas encheleia, and 1 was $A$. veronii bv. veronii. Disc diffusion method for antibiotic susceptibility testing was conducted as described by Vivekanandhan et al. (2002). The Aeromonas strains were tested against the following antibiotic discs (Oxoid, Basingstoke, Hampshire, United Kingdom): amikacin $(30 \mu \mathrm{g})$, ampicillin $(10 \mu \mathrm{g})$, cefazolin $(30 \mu \mathrm{g})$, ceftriaxone $(30 \mu \mathrm{g})$, chloramphenicol $(30 \mu \mathrm{g})$, gentamicin $(10 \mu \mathrm{g})$, kanamycin $(30 \mu \mathrm{g})$, nalidixic acid $(30 \mu \mathrm{g})$, streptomycin $(10 \mu \mathrm{g})$, sulphamethoxazole $(25 \mu \mathrm{g})$, tetracycline $(30 \mu \mathrm{g})$, trimethoprim $(5 \mu \mathrm{g})$, and trimethoprimsulphamethoxazole (1:19) $(25 \mu \mathrm{g})$. After enrichment in Brain Heart Infusion Broth at $35^{\circ} \mathrm{C}$ for 6 to $8 \mathrm{~h}$, the cultures were streaked on Mueller-Hinton agar plates using a cotton swab. With an antibiotic disc dispenser (Oxoid, Basingstoke, Hampshire, United Kingdom), the discs were placed on the agar surface. After $30 \mathrm{~min}$ of prediffusion time, the plates were incubated at $35{ }^{\circ} \mathrm{C}$ for $24 \mathrm{~h}$ before the inhibition zones were measured and compared with the susceptible control strain, Escherichia coli ATCC 25922, whose susceptibility pattern was as expected. All the tests were performed in duplicates, and when results were different, the experiment was repeated to resolve the discrepancy. The zones of growth inhibition were evaluated according to the Clinical and Laboratory Standards Institute (CLSI, 2006). Statistical significance $\left(P\right.$ value) was calculated using Pearson $\chi^{2}$ test in terms of number of resistance/intermediate resistance strains and susceptible strains in the integron-positive and integronnegative groups.

\subsection{DNA extraction and polymerase chain reaction amplification of integrase genes}

The strains were cultured in trypticase soy broth at $37^{\circ} \mathrm{C}$ for $24 \mathrm{~h}$. After harvest, the DNA was extracted using Puregene DNA Isolation Kit (Model D6000A; Gentra System, Minneapolis, MN). To determine whether the Aeromonas isolates carry integrons, we used polymerase chain reaction (PCR) amplification to detect class 1 and class 2 integrase genes, intI1 (IntI1-F/-R) and intI2 (IntI2-F/-R), respectively (Mazel et al., 2000). The primers used for the amplification of these genes and the predicted sizes of the amplification products are listed in Table 1. DNA samples ( $5 \mathrm{ng}$ per reaction mixture) were amplified in a $25 \mu \mathrm{L}$ reaction mixture consisting of $50 \mathrm{mmol} / \mathrm{L}$ potassium chloride, $10 \mathrm{mmol} / \mathrm{L}$ Tris chloride ( $\mathrm{pH} 8.3$ ), $1.25 \mathrm{mmol} / \mathrm{L}$ magnesium chloride, $200 \mu \mathrm{mol} / \mathrm{L}$ (each) deoxyribonucleotide triphosphate, $2.0 \mu \mathrm{mol} / \mathrm{L}$ primers, and $1.5 \mathrm{U}$ of FastStart Taq DNA

Table 1

Primers used for PCR analysis of integrons

\begin{tabular}{|c|c|c|c|c|}
\hline Primer & Nucleotide sequence $\left(5^{\prime}\right.$ to $\left.3^{\prime}\right)$ & Target & Product size $(b p)$ & Reference \\
\hline IntI1-F & GGGTCAAGGATCTGGATTTCG & intII & 483 & Mazel et al., 2000 \\
\hline IntI1-R & ACATGGGTGTAAATCATCGTC & & & \\
\hline IntI2-F & CACGGATATGCGACAAAAAGGT & intI2 & 788 & Mazel et al., 2000 \\
\hline IntI2-R & GTAGCAAACGAGTGACGAAATG & & & \\
\hline Call-F & TTATGGAGCAGCAACGATGT & Class 1 integron & Variable & This study \\
\hline Cal1-R & CTGTGAGCAATTATGTGCTT & Variable region & & \\
\hline A16SF & GGGAGTGCCTTCGGGAATCAGA & $16 \mathrm{~S}$ rRNA & 356 & Wang et al., 2003 \\
\hline A16SR & TCACCGCAACATTCTGATTTG & & & \\
\hline
\end{tabular}


polymerase (Roche Diagnostic, Mannheim, Germany). Amplifications were performed with a model 9700 DNA thermal cycler (Applied Biosystems, Foster City, CA). Conditions for amplification using the IntI1 and IntI2 primers were as follows: $94^{\circ} \mathrm{C}$ for $5 \mathrm{~min}$, followed by 30 cycles of 94 ${ }^{\circ} \mathrm{C}$ for $30 \mathrm{~s} ; 62{ }^{\circ} \mathrm{C}$ for $30 \mathrm{~s}$; and $72{ }^{\circ} \mathrm{C}$ for $60 \mathrm{~s}$. Conditions for amplification using the Call primers were as follows: $94{ }^{\circ} \mathrm{C}$ for $5 \mathrm{~min}$, followed by 30 cycles of $94^{\circ} \mathrm{C}$ for $30 \mathrm{~s}, 57^{\circ} \mathrm{C}$ for $30 \mathrm{~s}$, and $72{ }^{\circ} \mathrm{C}$ for $120 \mathrm{~s}$. If no amplification of the targeted gene was observed, then amplification of a $356 \mathrm{bp}$ fragment of 16S rRNA sequence was used as a positive control and distilled water (without DNA template) as a negative control. The sequence of the primers and the PCR operating conditions for the 16S rDNA are as described by Wang et al. (2003).

\subsection{Amplification and sequencing of gene cassette regions}

The gene cassette regions for class 1 integrons were amplified with primer pairs Call-F/Call-R. To determine whether different isolates carry identical gene cassette, we characterized the cassette genes of every isolate. That is, each cassette gene PCR amplification product was sequenced. To analyze the sequences of the gene cassette regions of the integrons, we cloned the PCR products into pCRII-TOPO vector (Invitrogen, Carlsbad, CA) and transformed it into $E$. coli $\mathrm{DH} 5 \alpha$ cells. Sequencing reactions were performed using a double-stranded plasmid preparation by dideoxy chain termination with T7 and SP6 primers. The nucleotide sequences of the integron gene of Aeromonas strains have been submitted to the GenBank nucleotide sequence database under accession numbers DQ462518, DQ462519, DQ462520, DQ515960, DQ519078, EF090608, and EF422367.

\section{Results}

Class 1 and class 2 integrons were analyzed in 133 Aeromonas strains, and PCR amplification was used to detect class 1 and class 2 integrase genes. Among the 133 isolates amplified, intI1 gene cassette regions were amplified in 74 isolates, but none of the isolates was positive in PCR assays specific for the int $I 2$ gene. For the detection of class 1 integron cassette (variable regions) in all intI1-positive isolates, PCR was performed with primers (Cal1-F/Cal1-R) for the $5^{\prime}$ and $3^{\prime}$ conserved segments. Among the 74 isolates carrying intII, 50 isolates were "empty" with no gene cassette inserted between the conserved segments of the integron. The other 24 isolates carried gene cassette in class 1 integrons; the sizes of these gene cassette regions ranged from 0.9 to $2.1 \mathrm{~kb}$. Upon sequencing the entire integrons, 10 different gene cassettes were identified, including genes encoding for resistance to trimethoprim (dfrA1, dfrA5), $\beta$-lactam antibiotics (oxa2), chloramphenicol (catB3, catB8), and aminoglycosides (aadA1, aadA2); qacE2 encoding a small protein that confers resistance to quaternary ammonium compounds; as

Table 2

Characteristics of the integrons-containing Aeromonas isolates

\begin{tabular}{|c|c|c|c|c|c|c|}
\hline Strain no. & Species & Origin & Gene cassettes & GenBank accession no. & Size (bp) & Antibiotic resistance profile \\
\hline 170 & A. caviae & $\mathrm{F}$ & $\operatorname{aadAl}$ & DQ462518 & 938 & AM, KZ, RL, S, SXT, W \\
\hline 175 & A. caviae & $\mathrm{F}$ & aadA1 & & 938 & $\mathrm{AM}, \mathrm{KZ}, \mathrm{RL}, \mathrm{TE}, \mathrm{W}$ \\
\hline 27 & A. veronii bv. sobria & A & qacE2/orfD & DQ462520 & 939 & $\mathrm{AM}, \mathrm{NA}, \mathrm{RL},(\mathrm{S})^{\mathrm{a}}, \mathrm{TE}$ \\
\hline 28 & A. hydrophila & A & qacE2/orfD & & 939 & AM, (KZ), RL, (W) \\
\hline 40 & A. hydrophila & A & qacE2/orfD & & 939 & $\mathrm{AM}, \mathrm{KZ}, \mathrm{RL},(\mathrm{S}), \mathrm{W}$ \\
\hline 43 & A. veronii bv. sobria & A & qacE2/orfD & & 939 & AM, KZ, (K), RL, (S), (W) \\
\hline 45 & A. caviae & A & qacE2/orfD & & 939 & $\mathrm{AM}, \mathrm{KZ}, \mathrm{NA}, \mathrm{RL}, \mathrm{TE}$ \\
\hline 50 & A. caviae & $\mathrm{F}$ & qacE2/orfD & & 939 & $\mathrm{AM}, \mathrm{KZ}, \mathrm{RL}$ \\
\hline 55 & A. caviae & $\mathrm{A}$ & qacE2/orfD & & 939 & $\mathrm{AM}, \mathrm{C}, \mathrm{KZ}, \mathrm{RL}, \mathrm{TE}$ \\
\hline 66 & A. veronii bv. sobria & $\mathrm{A}$ & qacE2/orfD & & 939 & $\mathrm{AM}, \mathrm{C}, \mathrm{KZ}, \mathrm{NA}, \mathrm{RL}, \mathrm{TE}$ \\
\hline 114 & A. hydrophila & $\mathrm{F}$ & $\mathrm{bal}($ oxa2)/orfD & DQ519078 & 1278 & $\mathrm{AM},(\mathrm{KZ}), \mathrm{RL}$ \\
\hline 333 & A. hydrophila & $\mathrm{F}$ & catB8/aadA1 & EF090608 & 1653 & $\mathrm{AM}, \mathrm{KZ}, \mathrm{RL}, \mathrm{S}$ \\
\hline 701 & A. hydrophila & $\mathrm{P}$ & catB3/aadA1 & DQ462519 & 1653 & AM, KZ, NA, RL,(S) \\
\hline 723 & A. caviae & $\mathrm{P}$ & catB3/aadA1 & & 1653 & $\mathrm{AM}, \mathrm{KZ}, \mathrm{NA}, \mathrm{RL}, \mathrm{TE}$ \\
\hline 727 & A. hydrophila & $\mathrm{P}$ & catB3/aadA1 & & 1653 & AM, KZ, NA, RL,(TE) \\
\hline 745 & A. hydrophila & $\mathrm{P}$ & catB3/aadA1 & & 1653 & AM, KZ, NA, RL, TE, W \\
\hline 752 & A. veronii bv. sobria & $\mathrm{P}$ & catB3/aadA1 & & 1653 & $\mathrm{AM},(\mathrm{KZ}), \mathrm{NA}, \mathrm{RL},(\mathrm{S}), \mathrm{TE}, \mathrm{W}$ \\
\hline 758 & A. hydrophila & $\mathrm{P}$ & catB3/aadA1 & & 1653 & $\mathrm{AM}, \mathrm{KZ}, \mathrm{NA}, \mathrm{RL}, \mathrm{S}, \mathrm{W}$ \\
\hline 38 & A. veronii bv. sobria & A & $d f r 12 / o r f F / a a d A 2$ & DQ515960 & 1842 & AM, C, K, NA, RL, S, SXT, (TE), W \\
\hline 67 & A. veronii bv. sobria & $\mathrm{A}$ & dfr $12 /$ orfF/aadA2 & & 1842 & $\mathrm{AM}, \mathrm{C}, \mathrm{K}, \mathrm{NA}, \mathrm{RL}, \mathrm{S}, \mathrm{TE}, \mathrm{SXT}, \mathrm{W}$ \\
\hline 74 & A. veronii bv. sobria & A & dfr12/orfF/aadA2 & & 1842 & AM, C, K, KZ, NA, RL, S, SXT, TE, W \\
\hline 180 & A. caviae & $\mathrm{F}$ & dfr12/orfF/aadA2 & & 1842 & AM, K, KZ, NA, RL, S, SXT, (TE), W \\
\hline 334 & A. hydrophila & $\mathrm{F}$ & dfr12/orfF/aadA2 & & 1842 & $\mathrm{AM}, \mathrm{K}, \mathrm{KZ}, \mathrm{RL}, \mathrm{SXT}, \mathrm{TE}, \mathrm{W}$ \\
\hline 168 & A. encheleia & $\mathrm{F}$ & dfr2d/catB3/aadA1 & EF422367 & 2061 & AM, C, KZ, NA, RL, (S), SXT, TE, W \\
\hline
\end{tabular}

$\mathrm{F}=$ foodborne outbreak-suspect samples; $\mathrm{A}=$ aquatic animal; $\mathrm{P}=$ poultry; $\mathrm{AM}=$ ampicillin; $\mathrm{C}=$ chloramphenicol; $\mathrm{K}=$ kanamycin; $\mathrm{KZ}=$ cefazolin; $\mathrm{NA}=$ nalidixic acid; $\mathrm{RL}=$ sulphamethoxazole; $\mathrm{S}=$ streptomycin; $\mathrm{SXT}=$ trimethoprim-sulphamethoxazole; $\mathrm{TE}=$ tetracycline; $\mathrm{W}=$ trimethoprim.

${ }^{\text {a }}$ Parentheses indicate intermediate resistance. 
Table 3

Antibiotic susceptibility of integron-positive and integron-negative strains of Aeromonas spp.

\begin{tabular}{|c|c|c|c|c|c|c|c|}
\hline \multirow[t]{2}{*}{ Antibiotics $(\mu \mathrm{g})^{\mathrm{a}}$} & \multicolumn{3}{|c|}{ Integron positive $(n=24)$} & \multicolumn{3}{|c|}{ Integron negative $(n=95)$} & \multirow[t]{2}{*}{$P^{\mathrm{b}}$} \\
\hline & $\% \mathrm{R}$ & $\%$ I & $\% \mathrm{~S}$ & $\% \mathrm{R}$ & $\%$ I & $\% \mathrm{~S}$ & \\
\hline Kanamycin (30) & 20.8 & 4.2 & 75.0 & 1.1 & 2.1 & 96.8 & $<0.05$ \\
\hline Streptomycin (10) & 29.2 & 25.0 & 45.8 & 1.1 & 14.7 & 84.2 & $<0.05$ \\
\hline Cefazolin (30) & 75.0 & 12.5 & 12.5 & 72.1 & 10.7 & 17.2 & NS \\
\hline Chloramphenicol (30) & 25.0 & 0 & 75.0 & 2.1 & 2.1 & 95.8 & $<0.05$ \\
\hline Tetracycline (30) & 50.0 & 12.5 & 37.5 & 24.2 & 8.4 & 67.4 & $<0.05$ \\
\hline Trimethoprim-sulphamethoxazole (25) & 29.2 & 0 & 70.8 & 1.1 & 0 & 98.9 & $<0.05$ \\
\hline Sulphamethoxazole (25) & 100 & 0 & 0 & 69.5 & 1.1 & 29.5 & $<0.05$ \\
\hline Trimethoprim (5) & 50.0 & 8.3 & 41.7 & 6.3 & 3.2 & 90.5 & $<0.05$ \\
\hline Nalidixic acid (30) & 58.3 & 0 & 41.7 & 25.3 & 0 & 74.7 & $<0.05$ \\
\hline
\end{tabular}

$\mathrm{NS}=$ not statistically significant; $\mathrm{R}=$ resistance; $\mathrm{I}=$ intermediate resistance; $\mathrm{S}=$ susceptible.

a Concentration of disks.

b Statistical significance ( $P$ value) was calculated using Pearson $\chi^{2}$ test in terms of number of resistance/intermediate resistance strains and susceptible strains in the integron-positive and integron-negative groups.

well as 2 different ORFs (orfD and orfF) of unknown function. The most commonly found genes among class 1 integron were aadA genes. Two aadA genes (aadAl and aadA2) were detected in 5 different class 1 integrons. Four class 1 integrons carried aadAl and one carried aadA2. Two $d f r$ genes ( $d f r 2 d$ and $d f r 12)$ and 2 cat genes (catB3 and $c a t B 8$ ) were detected in 2 different class 1 integrons, respectively (Table 2 ).

Of the 24 amplified class 1 integron variable regions, 7 isolates were $1653 \mathrm{bp}$ in size. Although inserted regions were indistinguishable with respect to size, nucleotide sequencing showed that variable regions contained 2 gene cassettes: one was identified as aadA gene, and the other gene cassette was identified as cat gene orthology (catB3 and catB8). Similar results were also found in 10 isolates, which were about $940 \mathrm{bp}$ in size; 8 isolates carried both qacE2 and orfD (939 bp); and 2 isolates carried single aadAl (938 bp) (Table 2).

Antimicrobial resistance testing by disc diffusion was performed and evaluated according to the CLSI (2006). The susceptibility pattern for the integron containing strains is shown in Table 2, and the percentage of Aeromonas strains showing resistance against each antibiotic is given in Table 3. The data from integron-positive and integron-negative isolates were compared with relate integron carriage and resistance profile. All the strains were resistant to ampicillin followed by sulphamethoxazole and cefazolin with more than $70 \%$ of strains presenting full or intermediate resistance; however, all the tested strains were susceptible to amikacin, gentamicin, and ceftriaxone. The susceptibility to chloramphenicol, kanamycin, nalidixic acid, streptomycin, sulphamethoxazole, tetracycline, trimethoprim, and trimethoprim-sulphamethoxazole varied in integron-positive and integron-negative isolates. In the integron-positive strains, except cefazolin, the frequency of resistance to most of antimicrobial agents was significantly $(P<0.05)$ higher than integron-negative strains (Table 3). All of integron-positive Aeromonas spp. were multidrug resistant (resistant to 3 or more commonly used antibiotics). Resistance to more than 9 antibiotics was observed in 5 strains (nos. 38, 67, 74, 168, and 180), of which 2 were isolated from foodborne sample and 3 from fish. Most of the integron-positive isolates displayed resistance to multiple antibiotics compared with the integron-negative isolates.

\section{Discussion}

Class 1 integron and gene cassettes have been found in a number of different bacterial genera and appear to be prevalent in nature (Goldstein et al., 2001). Of the 133 strains analyzed, class 1 integron was identified in 24 $(18.0 \%)$ strains. This prevalence was higher than that reported by Rosser and Young (1999), who showed that $3.6 \%$ of Gram-negative bacteria in an estuarine environment contained the class 1 integron in UK. In contrast, other reports from clinical isolates revealed that the prevalence of class 1 integrons in other Gram-negative bacteria were 52\% in Taiwan (E. coli) (Chang et al., 2000), 54.6\% in Korea (E. coli) (Yu et al., 2003), 59\% in France (Enterobacteriaceae) (Sallen et al., 1995), and 9.4\% in China (Shigella spp.) (Pan et al., 2006). This dissimilarity may be due to the differences in bacterial genera or isolate sources. Despite the low prevalence in this study, high diversity of integrons was observed. Seven different class 1 integrons were detected, and all of the gene cassettes were described in other microorganisms (White and Rawlinson, 2001; Pai et al., 2003; Soler Bistue et al., 2006; Williams et al., 2006), indicating the high potential of these structures to be transferred within microorganisms because of their transportation within plasmids or conjugative transposons. Our results also support the hypothesis that integrons provide a very efficient strategy for the acquisition and dissemination of new antibiotic resistance genes.

In about $67.6 \%$ strains harboring intII, gene cassette amplicon was not obtained or the amplicon size was less than $200 \mathrm{bp}$. This may be because the inserted gene cassette regions were too large to be amplified by conventional PCR techniques, or such integrons may lack the $3^{\prime}$ conserved segment generally associated with this class of integron 
(Barlow et al., 2004), or amplification products of approximately $150 \mathrm{bp}$ probably corresponded to empty structures (Bissonnette and Roy, 1992). Poole et al. (2006) also reported that roughly half of the integrons characterized did not contain integron-associated gene cassettes, and some of the integrons lacked the $3^{\prime}$ conserved region.

Although only 8 integron-containing strains isolated from foodborne samples were reported in this study, they contained 6 different integrons (Table 2). On the other hand, 6 strains isolated from different raw meats of poultry carry the same integron containing catB3 and aadA1 gene cassettes, and 1 strain (no. 333) isolated from foodborne sample carries the integron containing catB8 and aadAl gene cassettes. However, integron carrying $d f r 12, \operatorname{orfF}$, and aadA2 was found in $A$. caviae (no. 180), A. veronii bv. sobria (nos. 38, 67, and 74), and A. hydrophila (no. 334) isolated from foodborne and aquatic animal samples. An identical integron was reported in an $E$. coli isolate from the United States (Williams et al., 2006) and Taiwan (Chang et al., 2000), and in Staphylococcus aureus isolate from South China (Shi et al., 2006). These results reveal that the same integron can disseminate in different bacterial species or genera, in different sample sources, and in different areas of the world. The most frequently detected resistance genes were aminoglycoside adenyltransferase genes (aadA1 and aadA2) that confer resistance to streptomycin and spectinomycin. This similar observation was reported for motile aeromonads isolated from bovine feces in Australia (Barlow et al., 2004) and Gram-negative bacteria isolated from aquatic environment (Rosser and Young, 1999).

Many classes of antimicrobial agents, such as aminoglycosides, chloramphenicol, tetracycline, and trimethoprimsulphamethoxazole have been reported to be active against aeromonads (Clark, 1992; Koehler and Ashdown, 1993; Zhao et al., 2001). Multiple resistance phenotypes were observed in class 1 integron-containing isolates in our study (Table 2). Integron and gene cassettes have been identified as a primary source of resistance and are suspected to serve as reservoirs of antimicrobial resistance genes within microbial populations (Bass et al., 1999; Ochman et al., 2000). Trimethoprim combination with sulphamethoxazole is commonly used for the treatment of gastroenteritis (Zhao et al., 2001). Among the integron-positive isolates, significant increase in the number of strains resistant to trimethoprim and trimethoprim-sulphamethoxazole was observed. A high correlation between the presence of integrons carrying $d f r$ gene and resistance to trimethoprim and trimethoprimsulphamethoxazole was observed (Table 2). Trimethoprim is a broad-spectrum antimicrobial agent active against enteric pathogens, and trimethoprim alone or in combination with sulphamethoxazole has been commonly used to treat infection (Yu et al., 2004). Of the 133 tested strains, 7 isolates were trimethoprim-sulphamethoxazole resistant, and among these, 6 have an integron carrying $d f r$ gene, 5 harboring $d f r 12$, and 1 harboring $d f r 2 d$. This suggests that class 1 integrons are an important genetic element for resistance to trimethoprim and trimethoprim-sulphamethoxazole among Aeromonas isolates. Fifteen integron-positive isolates contained the $\operatorname{adA} A 1$ or $\operatorname{aadA2}$, but not all isolates are resistant to streptomycin. Resistance to streptomycin was not observed in most isolates that harbor aadA1, but resistance to the streptomycin (except no. 334) and the closely related kanamycin was seen in isolates containing aadA2 in the integrons (Table 2). Similar observations were made in several previous reports. Pan et al. (2006) reported that resistance to streptomycin was not observed in Shigella spp. isolates harboring a class 1 integron that contains different $\operatorname{aadA}$ cassette. Roe et al. (2003) observed that 3 E. coli isolates, harboring a class 1 integron that contains a single cassette of $\operatorname{aadA1}$, were resistant to kanamycin but not resistant to streptomycin. Conjugal transfer of plasmids harboring aadAl gene cassette to a strain of Hafnia alvei has been reported; however, the transfer did not confer resistance to streptomycin (Zhao et al., 2001), and it was suggested that expression of the inserted gene cassette by the integron promoter was inefficient. In our study, 7 of the 8 isolates carrying catB (chloramphenicol acetyltransferase) genes in integrons are sensitive to chloramphenicol; this may be due to the inefficient expression as reported by Zhao et al. (2001). Potrykus and Wegrzyn (2001) found low levels of acetyl coenzyme A in cat-expressing E. coli CM2555 in the presence of chloramphenicol, which led the bacterium to be sensitive to this antibiotic. The results indicate that integronbearing strains may not always express the resistance to antibiotics. Furthermore, many isolates showed resistance to antibiotics but did not possess the corresponding antibiotic resistance gene cassettes within the integrons characterized from such isolates. Lee et al. (2001) reported that not all of the $d f r A 1$ genes were found to be associated with integron gene cassettes. It is suggested that such resistances are encoded by nonintegron elements. In our study also, 5 integron-positive strains (nos. 38, 55, 66, 67, and 74) were resistant to chloramphenicol, but cat cassettes were not found in the integron, implying the nonintegron sources of this gene. The antimicrobial phenotype probably relate to nonenzymatic chloramphenicol resistance $(\mathrm{cmlA})$ gene or other antimicrobial mechanism. We also observed that the $d f r$ gene cassettes are situated closer to the promoter region ( $5^{\prime}$ terminal) of the integron and therefore were probably expressed more efficiently then other gene cassettes.

In conclusion, this study demonstrated that class 1 integrons are an important genetic element for resistance to trimethoprim combination with sulphamethoxazole among Aeromonas isolates. These bacterial strains are potential reservoirs for antimicrobial resistance genes and play an important role in transfer of antibiotic resistance gene among bacterial populations in nature. To our knowledge, arrangement of some of the gene cassettes in this study was never reported in Aeromonas strains. However, a similar gene cassette array of $d f r 2 d / c a t B 3 / a a d A 1$ found in A. encheleia (no. 168) had already been reported in A. hydrophila (GenBank accession number AY751518). All of these 
10 gene cassettes found among Aeromonas spp. isolates in this study are also often present in clinical and environmental isolates of the Gram-negative bacteria. These findings suggest that the transfer of antibiotic resistance genes can occur through gene cassettes on class 1 integrons among Aeromonas spp. and other bacteria.

\section{Acknowledgments}

This study was supported by the Department of Health, Taiwan (BFDA94). We are grateful to Dr. Ammaiyappan Selvam for critical review of the manuscript.

\section{References}

Barlow RS, Pemberton JM, Desmarchelier PM, Gobius KS (2004) Isolation and characterization of integron-containing bacteria without antibiotic selection. Antimicrob Agents Chemother 48:838-842.

Bass L, Liebert CA, Lee MD, Summers AO, White DG, Thayer SG, Maurer JJ (1999) Incidence and characterization of integrons, genetic elements mediating multiple-drug resistance, in avian Escherichia coli. Antimicrob Agents Chemother 43:2925-2929.

Bissonnette L, Roy PH (1992) Characterization of In0 of Pseudomonas aeruginosa plasmid pVS1, an ancestor of integrons of multiresistance plasmids and transposons of gram-negative bacteria. $J$ Bacteriol 174:1248-1257.

Chang CY, Chang LL, Chang YH, Lee TM, Chang SF (2000) Characterisation of drug resistance gene cassettes associated with class 1 integrons in clinical isolates of Escherichia coli from Taiwan ROC. $J$ Med Microbiol 49:1097-1102.

Clark RB (1992) Antibiotic susceptibilities of the Vibrionaceae to meropenem and other antimicrobial agents. Diagn Microbiol Infect Dis 15:453-455.

Clinical and Laboratory Standards Institute (2006) Performance Standards for Antimicrobial Susceptibility Testing; Sixteenth Informational Supplement CLSI Document M100-S16. Wayne (PA): Clinical and Laboratory Standards Institute.

Collis CM, Hall RM (1995) Expression of antibiotic resistance genes in the integrated cassettes of integrons. Antimicrob Agents Chemother 39:155-162.

Collis CM, Grammaticopoulos G, Briton J, Stokes HW, Hall RM (1993) Site-specific insertion of gene cassettes into integrons. Mol Microbiol 9:41-52.

Collis CM, Kim MJ, Stokes HW, Hall RM (2002) Integron-encoded IntI integrases preferentially recognize the adjacent cognate attI site in recombination with a 59-be site. Mol Microbiol 46:1415-1427.

Fluit AC, Schmitz FJ (1999) Class 1 integrons, gene cassettes, mobility, and epidemiology. Eur J Clin Microbiol Infect Dis 18:761-770.

Goldstein C, Lee MD, Sanchez S, Hudson C, Phillips B, Register B, Grady M, Liebert C, Summers AO, White DG, Maurer JJ (2001) Incidence of class 1 and 2 integrases in clinical and commensal bacteria from livestock, companion animals, and exotics. Antimicrob Agents Chemother 45:723-726.

Goñi-Urriza M, Pineau L, Capdepuy M, Roques C, Caumette P, Quentin C (2000) Antimicrobial resistance of mesophilic Aeromonas spp. isolated from two European rivers. J Antimicrob Chemother 46:297-301.

Hall RM, Stokes HW (1993) Integrons, novel DNA elements which capture genes by site-specific recombination. Genetica 90:115-132.

Kirov SM (1997) Aeromonas and Plesiomonas. In Food Microbiology, Fundamentals and Frontiers. Eds, MP Doyle, LR Beuchat, and TJ Montville. Washington (DC): ASM Press. pp. 265-287.

Ko WC, Yu KW, Liu CY, Huang CT, Leu HS, Chuang YC (1996) Increasing antibiotic resistance in clinical isolates of Aeromonas strains in Taiwan. Antimicrob Agents Chemother 40:1260-1262.
Koehler JM, Ashdown LR (1993) In vitro susceptibilities of tropical strains of Aeromonas species from Queensland, Australia, to 22 antimicrobial agents. Antimicrob Agents Chemother 37:905-907.

Lee JC, Oh JY, Cho JW, Park JC, Kim JM, Seol SY, Cho DT (2001) The prevalence of trimethoprim-resistance-conferring dihydrofolate reductase genes in urinary isolates of Escherichia coli in Korea. J Antimicrob Chemother 47:599-604.

Martinez E, de la Cruz F (1990) Genetic elements involved in Tn21 sitespecific integration, a novel mechanism for the dissemination of antibiotic resistance genes. EMBO J 9:1275-1281.

Martinez-Freijo P, Fluit AC, Schmitz F-J, Verhoef J, Jones ME (1999) Many class 1 integrons comprise distinct stable structures occurring in different species of Enterobacteriaceae isolated from widespread geographic regions in Europe. $J$ Antimicrob Chemother 43: 686-689.

Mazel D, Dychinco B, Webb VA, Davies J (2000) Antibiotic resistance in the ECOR collection, integrons and identification of a novel aad gene. Antimicrob Agents Chemother 44:1568-1574.

Neyts K, Huys G, Uyttendaele M, Swings J, Debevere J (2000) Incidence and identification of mesophilic Aeromonas spp. from retail foods. Lett Appl Microbiol 31:359-363.

Nield BS, Holmes AJ, Gillings MR, Recchia GD, Mabbutt BC, Nevalainen KM, Stokes HW (2001) Recovery of new integron classes from environmental DNA. FEMS Microbiol Lett 195:59-65.

Ochman H, Lawrence JG, Groisman EA (2000) Lateral gene transfer and the nature of bacterial innovation. Nature 405:299-304.

Pai H, Byeon JH, Yu S, Lee BK, Kim S (2003) Salmonella enterica serovar typhi strains isolated in Korea containing a multidrug resistance class 1 integron. Antimicrob Agents Chemother 47: 2006-2008.

Palú AP, Gomes LM, Miguel MA, Balassiano IT, Queiroz ML, FreitasAlmeida AC, de Oliveira SS (2006) Antimicrobial resistance in food and clinical Aeromonas isolates. Food Microbiol 23:504-509.

Pan JC, Ye R, Meng DM, Zhang W, Wang HQ, Liu KZ (2006) Molecular characteristics of class 1 and class 2 integrons and their relationships to antibiotic resistance in clinical isolates of Shigella sonnei and Shigella flexneri. J Antimicrob Chemother 58:288-296.

Partridge SR, Recchia GD, Scaramuzzi C, Collis CM, Stokes HW, Hall RM (2000) Definition of the attII site of class 1 integrons. Microbiology 146:2855-2864.

Ploy MC, Lambert T, Couty JP, Denis F (2000) Integrons, an antibiotic resistance gene capture and expression system. Clin Chem Lab Med 38:483-487.

Poole TL, Callaway TR, Bischoff KM, Warnes CE, Nisbet DJ (2006) Macrolide inactivation gene cluster $m p h A-m r x-m p h R$ adjacent to a class 1 integron in Aeromonas hydrophila isolated from a diarrhoeic pig in Oklahoma. J Antimicrob Chemother 57:31-38.

Potrykus J, Wegrzyn G (2001) Chloramphenicol-sensitive Escherichia coli strain expressing the chloramphenicol acetyltransferase (cat) gene. Antimicrob Agents Chemother 45:3610-3612.

Radu S, Ahmad N, Ling FH, Reezal A (2003) Prevalence and resistance to antibiotics for Aeromonas species from retail fish in Malaysia. Int $J$ Food Microbiol 81:261-266.

Roe MT, Vega E, Pillai SD (2003) Antimicrobial resistance markers of class 1 and class 2 integron-bearing Escherichia coli from irrigation water and associated sediments. Emerg Infect Dis 9:822-826.

Rosser SJ, Young HK (1999) Identification and characterization of class 1 integrons in bacteria from an aquatic environment. J Antimicrob Chemother 44:11-18.

Sallen B, Rajoharison A, Desvarenne S, Mabilat C (1995) Molecular epidemiology of integron-associated antibiotic resistance genes in clinical isolates of Enterobacteriaceae. Microb Drug Resist 1:195-202.

Schmidt AS, Bruun MS, Dalsgaard I, Larsen JL (2001) Incidence, distribution, and spread of tetracycline resistance determinants and integron-associated antibiotic resistance genes among motile aeromonads from a fish farming environment. Appl Environ Microbiol 67:5675-5682. 
Shi L, Zheng M, Xiao Z, Asakura M, Su J, Li L, Yamasaki S (2006) Unnoticed spread of class 1 integrons in gram-positive clinical strains isolated in Guangzhou China. Microbiol Immunol 50:463-467.

Soler Bistue AJC, Martin FA, Petroni A, Faccone D, Galas M, Tolmasky ME, Zorreguieta A (2006) Vibrio cholerae InV117, a class 1 integron harboring $a a c\left(6^{\prime}\right)-I b$ and $b l a_{\mathrm{CTX}-\mathrm{M}-2}$, is linked to transposition genes. Antimicrob Agents Chemother 50:1903-1907.

Vila J, Marco F, Soler L, Chacon M, Figueras MJ (2002) In vitro antimicrobial susceptibility of clinical isolates of Aeromonas caviae, Aeromonas hydrophila and Aeromonas veronii biotype sobria. J Antimicrob Chemother 49:701-702.

Vivekanandhan G, Savithamani K, Hatha AA, Lakshmanaperumalsamy P (2002) Antibiotic resistance of Aeromonas hydrophila isolated from marketed fish and prawn of South India. Int J Food Microbiol 76: $165-168$.

Wang G, Clark CG, Liu C, Pucknell C, Munro CK, Kruk TM, Caldeira R, Woodward DL, Rodgers FG (2003) Detection and characterization of the hemolysin genes in Aeromonas hydrophila and Aeromonas sobria by multiplex PCR. J Clin Microbiol 41:1048-1054.
White PA, Rawlinson WD (2001) Current status of the aadA and $d f r$ gene cassette families. J Antimicrob Chemother 47:495-496.

Williams LE, Detter C, Barry K, Lapidus A, Summers AO (2006) Facile recovery of individual high-molecular-weight, low-copy-number natural plasmids for genomic sequencing. Appl Environ Microbiol 72: 4899-4906.

Yu HS, Lee JC, Kang HY, Ro DW, Chung JY, Jeong YS, Tae SH, Choi CH, Lee EY, Seol SY, Lee YC, Cho DT (2003) Changes in gene cassettes of class 1 integrons among Escherichia coli isolates from urine specimens collected in Korea during the last two decades. J Clin Microbiol 41:5429-5433.

Yu HS, Lee JC, Kang HY, Jeong YS, Lee EY, Choi CH, Tae SH, Lee YC, Seol SY, Cho DT (2004) Prevalence of $d f r$ genes associated with integrons and dissemination of $d f r A 17$ among urinary isolates of Escherichia coli in Korea. $J$ Antimicrob Chemother 53:445-450.

Zhao S, White DG, Ge B, Ayers S, Friedman S, English L, Wagner D, Gaines S, Meng J (2001) Identification and characterization of integronmediated antibiotic resistance among Shiga toxin-producing Escherichia coli isolates. Appl Environ Microbiol 67:1558-1564. 